\title{
Which Surgeries Are the Best Choice for Chronic Pancreatitis: A Network Meta-Analysis of Randomized Controlled Trials
}

\author{
Yu Mou ${ }^{1 \dagger}$, Yi Song ${ }^{2 \dagger}$, Hong-Yu Chen ${ }^{1}$, Xing Wang ${ }^{1}$, Wei Huang ${ }^{3}$, Xu-Bao Liu ${ }^{1}$ and \\ Neng-Wen $\mathrm{Ke}^{1 *}$ \\ ${ }^{1}$ Department of Pancreatic Surgery, West China Hospital, Sichuan University, Chengdu, China, ${ }^{2}$ Geriatrics Center, West \\ China Hospital, Sichuan University, Chengdu, China, ${ }^{3}$ Department of Integrated Traditional Chinese and Western Medicine, \\ West China Hospital, Sichuan University, Chengdu, China
}

\section{OPEN ACCESS}

Edited by:

Frederik Berrevoet,

Ghent University Hospital, Belgium

Reviewed by:

Isabella Frigerio,

Casa di cura Pederzoli, Italy

Joris Jaekers,

University Hospitals Leuven, Belgium

*Correspondence:

Neng-Wen Ke

kenengwen@scu.edu.cn

tThese authors have contributed equally to this work

Specialty section: This article was submitted to

Visceral Surgery,

a section of the journa

Frontiers in Surgery

Received: 20 October 2021 Accepted: 20 December 2021

Published: 03 February 2022

Citation:

Mou $Y$, Song $Y$, Chen $H-Y$, Wang $X$, Huang W, Liu X-B and Ke N-W (2022) Which Surgeries Are the Best Choice for Chronic Pancreatitis: A Network Meta-Analysis of Randomized

Controlled Trials.

Front. Surg. 8:798867.

doi: 10.3389/fsurg.2021.798867
Background: Surgery is an effective choice for the treatment of chronic pancreatitis (CP). However, there is no clear consensus regarding the best choice among the surgical procedures. The aim of this study is to conduct a network meta-analysis of randomized controlled trials comparing treatment outcomes to provide high-quality evidences regarding which is the best surgery for CP.

Methods: A systematic search of the PubMed (MEDLINE), SCIE, EMBASE, CENTRAL, and CDSR databases were performed to identify studies comparing surgeries for CP from the beginning of the databases to May 2020. Pain relief and mortality were the primary outcomes of interest.

Results: Ten studies including a total of 680 patients were identified for inclusion. PPPD had a better postoperative short-term pain relief and quality of life (QOL), but a worse pancreatic exocrine function deficiency and high morbidity. Berne had a significant postoperative long-term pain relief and mortality with a lower risk of pancreatic exocrine function deficiency.

Conclusion: The main surgical procedures including the PPPD, Beger procedure, Frey modification and Berne modification can efficaciously treat CP. The Berne modification may be first choice with better efficacy and less complications in pancreatic function, but the impact of postoperative QOL cannot be ignored. Furthermore, when the CP patients have a mass in the pancreatic head which cannot be distinguished from pancreatic cancer, the only legitimate choice should be PPPD or classical pancreaticoduodenectomy.

Keywords: chronic pancreatitis, pancreatectomy, abdominal pain, exocrine pancreatic insufficiency, network meta-analysis

\section{BACKGROUND}

Chronic pancreatitis (CP) is a progressive and irreversible fibroinflammatory disorder which is characterized by continuous destruction of the pancreatic parenchyma and fibrosis, leading to the intractable pain and poor quality of life (QOL). As the disease progresses, there is consecutive loss of pancreatic function and development of local complications (e.g., ductal obstruction, pancreatic 
pseudocysts, etc.) $(1,2)$. The risk of pancreatic cancer is increased in patients with CP (1). These recurrent or persistent pain and comorbidities make $\mathrm{CP}$ one of the most resource-consuming diseases $(3,4)$.

Since the tormenting pain is the predominant symptom of CP, the primary goal of the treatment is to mitigate the pain $(1,5-7)$. However, the exact mechanisms of abdominal pain in CP have not been fully elucidated. Therefore, adequate management of pain in CP remains a challenge (5). Traditionally, a conservative step-up approach has been advocated for pain treatment in $\mathrm{CP}$ which consists of medical, endoscopic, and surgical therapy (1, 6, 7 ). Research has proved a large proportion of patients refractory to medical therapy $(8,9)$. Endoscopic therapy is indicated in such patients when there is evidence of biliary or pancreatic ductal obstruction and symptomatic pseudocysts $(1,6,7)$. However, it has been shown in several randomized controlled trials (RCTs) (10-12) that endoscopic therapy is not as efficacious as surgery (either resection or drainage) in terms of pain relief. Cahen et al. $(11,12)$ reported that more than half of the patients who were initially randomized to endoscopic therapy eventually underwent surgery for pain control.

Therefore, increasing evidence supports that surgery, even early surgery (13-15), is an optional choice for the treatment of $\mathrm{CP}$. However, there are several surgical procedures for $\mathrm{CP}$, such as pylorus-preserving pancreaticoduodenectomy (PPPD), Beger procedure, Frey modification and so on. There is no clear consensus regarding the best choice among the surgical procedures. Several systematic reviews have tried to analyze the difference among surgical procedures for CP (14, 16-20); however, most of them included retrospective studies or only compared two surgical procedures. In the present study, we compared all surgical procedures for $\mathrm{CP}$ and each included study was RCT. The aim of this study was to conduct a meta-analysis of RCTs comparing treatment outcomes and operation time to provide high-quality evidence regarding which is the best surgical technique for CP.

\section{METHODS}

\section{Literature Search}

Electronic databases such as PubMed (Medline), Science Citation Index Expanded, EMBASE, Cochrane Central Register of Controlled Trials and the Cochrane Database of Systematic Reviews were searched for studies comparing surgical techniques for CP from the beginning of databases to May 2020. The following medical subject headings (MeSH) were used: "pancreaticoduodenectomy," "pancreatoduodenectomy," "Whipple," "pancreatoduodenal resection," "pylorus preserving pancreaticoduodenectomy," "PPPD," "Pancreaticojejunostomy," "Beger," "Frey" "Puestow or Partington-Rochelle," "pancreatic surgery," "randomized controlled trial," and "controlled clinical trial"; combinations of these headings were used for word searches. In the PubMed database, we used the following strategy:

Abbreviations: $\mathrm{CP}$, chronic pancreatitis; $\mathrm{PPPD}$, pylorus-preserving pancreaticoduodenectomy; QOL, quality of life; SCIE, Science Citation Index Expanded; RCT, randomized controlled trial; CI, confidence interval. (pancreaticoduodenectomy OR pancreatoduodenectomy OR "Whipple procedure" OR "pancreatoduodenal resection" OR PPPD OR Pancreaticojejunostomy OR "Beger procedure" OR "Frey procedure" OR "Frey modification" OR "Puestow procedure" OR "Partington-Rochelle") AND ("randomized controlled trial" OR "controlled clinical trial”). We performed a cross-reference search of all selected articles in case studies were missed during the initial database searches. The inclusion of articles was determined by the consensus of two authors; when this failed, a third author adjudicated.

\section{Inclusion and Exclusion Criteria}

All studies were scrutinized for eligibility by two authors using the following inclusion criteria: (1) studies described RCTs. Studies written in languages other than English were translated by a native speaker of that language who also holds a medical degree and with familiarity in surgery or in gastroenterology. (2) Human clinical trials compared surgical procedures for CP. (3) The full-text articles were published in peer-reviewed journals.

Studies were excluded if the following conditions existed: (1) they were case reports, reviews, letters, editorials or expert opinions; (2) the primary outcomes were unavailable; (3) they included surgery for indications other than CP including hepatopancreatobiliary malignancy, pancreas divisum, pancreatic hemorrhage or pancreatic infection, or they were studies pertaining only to drainage of cysts or pseudocysts and pancreatic transplant; and (4) they were trials comparing endoscopic vs. surgical procedures, or a surgical procedure vs. conservative treatment for CP.

\section{Outcomes of Interest}

Pain relief and mortality were the primary outcomes of interest. Secondary outcomes were QOL, new-onset endocrine and exocrine pancreatic insufficiency, and postoperation complications (including fistulas, postoperative hemorrhage, intra-abdominal abscesses, anastomotic leakage, sepsis and wound infections).

\section{Data Extraction}

Data were extracted by two independent authors using standardized proformas and included participant characteristics, study characteristics, data needed for the methodological quality assessment of the study, and primary and secondary outcomes, according to availability. Data regarding participant characteristics included number of participants in each group, age, sex, etiology, etc. Data regarding study characteristics included study design, sample size information, follow-up period, loss to follow-up, and surgical procedures compared. Means of the outcomes were used for meta-analytical synthesis by default. If medians rather than means were available in some studies, means were estimated as the medians when the samples were greater than 25 . With samples of any size smaller than 25 , the means were estimated using the following formula: (low end of range + median $^{*} 2+$ high end of range) $/ 4$. The standard deviations were estimated as range/ 4 when only a range was given (21). The risk of bias of all selected studies was assessed using the Cochrane Collaboration's tool for assessing risk of bias for RCTs. 


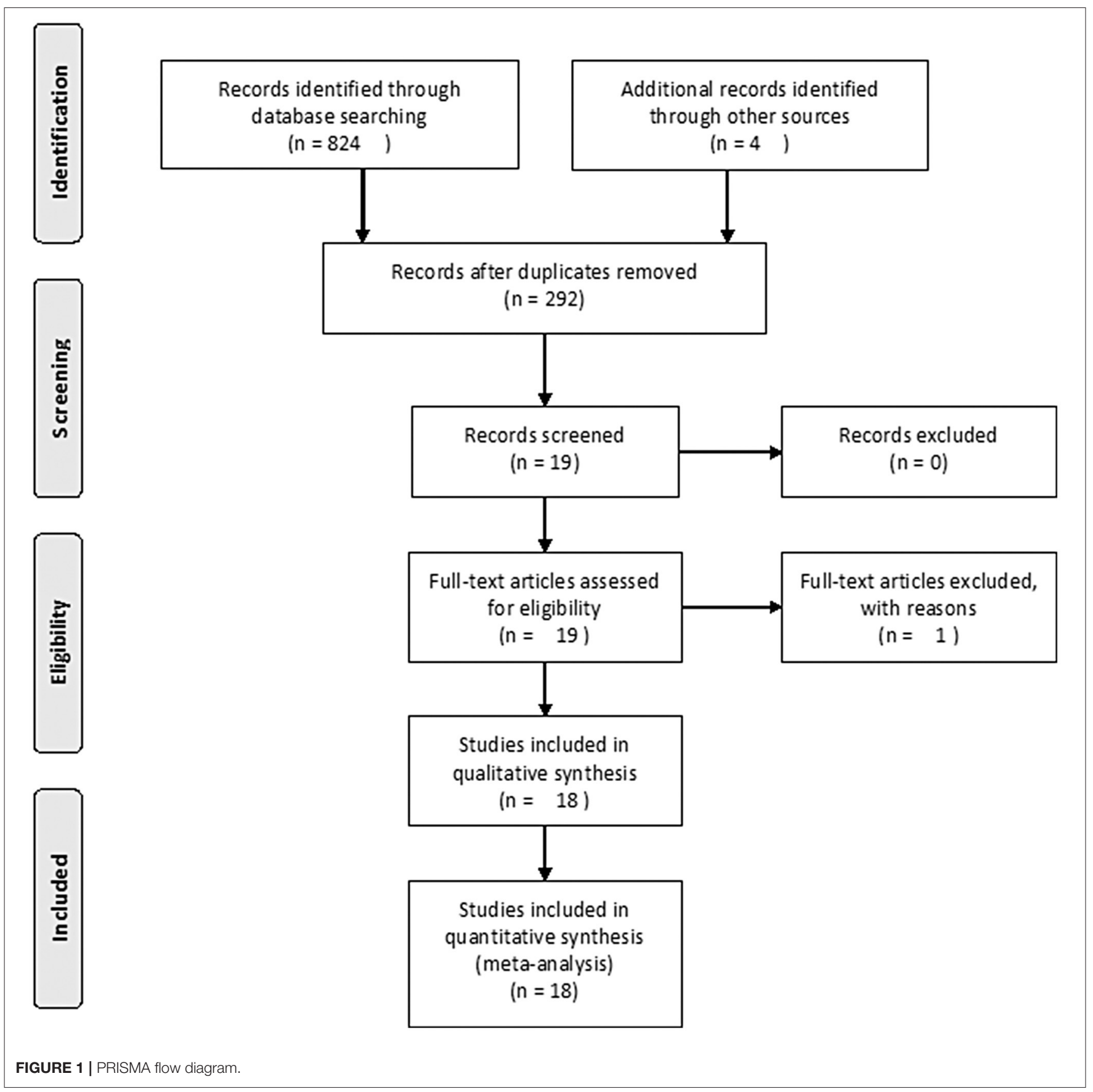

\section{Statistical Analysis}

The statistical analysis was performed using software R 4.0.3 (main packages include gemtc and rjags). A network of all surgical approaches was mapped. Contribution plots were performed to display contributions of each direct comparison in network meta-analysis. Continuous variables were estimated as weighted mean difference (WMD) with their corresponding 95\% confidence interval (CI), while categorical variables were expressed as odds ratio (OR) with 95\% CI. Heterogeneity was assessed using Chi-square tests and a $P<0.1$ was considered significant. $I^{2}$ statistic were used for the evaluation of statistical heterogeneity: an $I^{2}$ value of $50 \%$ or more was indicative of the presence of heterogeneity (22). The fixed effects models were initially applied (23), while the random effects model was used if the assumption of homogeneity of studies was rejected (24). A $P<0.05$ was considered significant in the meta-analytical synthesis. Descriptive methods were utilized if the data were considered to be inappropriate for meta-analytical synthesis.

\section{Ethics Statement}

The data used in this meta-analysis was derived from articles published in peer-reviewed journals. This study does no harm to 
TABLE 1 | Characteristics of included studies.

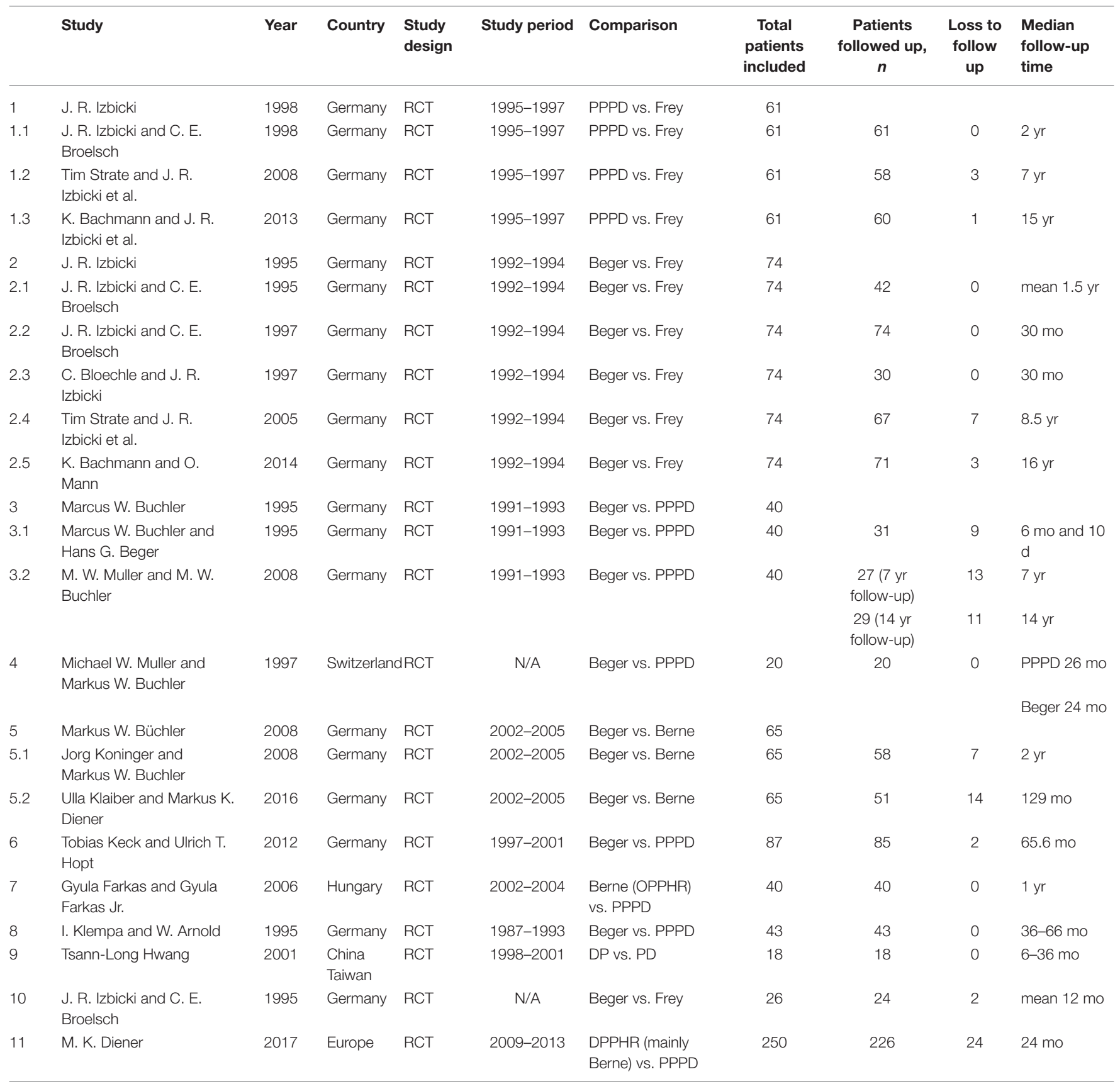

RCT, randomized controlled trial; PPPD, pylorus-preserving pancreaticoduodenectomy; DP, distal pancreatectomy; PD, pancreaticoduodenectomy; OPPHR, organ-preserving pancreatic head resection; DPPHR, duodenum-preserving pancreatic head resection; N/A, not applicable; yr, year(s); mo, month(s); d, day(s).

the subjects included in the study, so ethical approval and consent to participate is not necessary for this study.

\section{RESULTS}

\section{Study Selection}

The search strategy initially identified 292 relevant studies. Nineteen publications (25-43) with full-text were identified for detailed investigation after filtering the studies. Of these, two trials were described in eight publications (25-32), and two of the trials with long-term follow-up were described in four publications $(33,34,36,37)$. One study (41) had no data available. Finally, 11 studies were identified for inclusion with a total of 680 patients (Figure 1). Table 1 outlines the key design features of each study. Table 2 shows the characteristics of each study. One study compared PPPD with the Frey modification. Two studies compared the Beger procedure with the Frey modification. One study compared the Beger procedure with the 
TABLE 2 | Baseline patient demographics for all included studies.

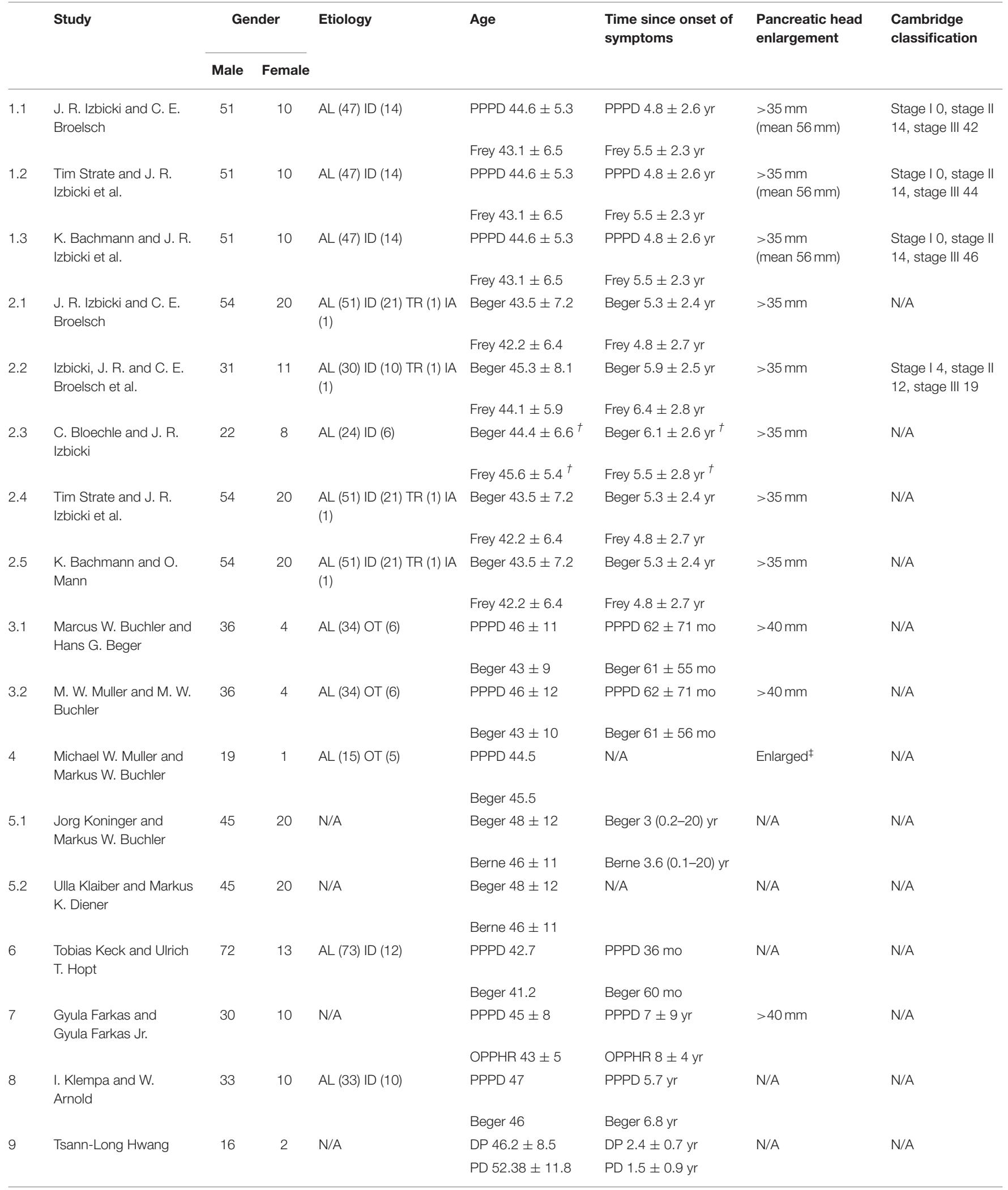


TABLE 2 | Continued

\begin{tabular}{|c|c|c|c|c|c|c|c|c|}
\hline & \multirow[t]{2}{*}{ Study } & \multicolumn{2}{|c|}{ Gender } & \multirow[t]{2}{*}{ Etiology } & \multirow[t]{2}{*}{ Age } & \multirow{2}{*}{$\begin{array}{l}\text { Time since onset of } \\
\text { symptoms }\end{array}$} & \multirow{2}{*}{$\begin{array}{l}\text { Pancreatic head } \\
\text { enlargement }\end{array}$} & \multirow{2}{*}{$\begin{array}{l}\text { Cambridge } \\
\text { classification }\end{array}$} \\
\hline & & Male & Female & & & & & \\
\hline \multirow[t]{2}{*}{10} & $\begin{array}{l}\text { J. R. Izbicki and C. E. } \\
\text { Broelsch }\end{array}$ & 19 & 7 & $\mathrm{AL}(21) \mathrm{IA}(1) \mathrm{ID}(4)$ & Beger 46.8 & Beger $5.9 \mathrm{yr}$ & $>35 \mathrm{~mm}$ & $\begin{array}{l}\text { Stage I 2, stage II } \\
6 \text {, stage III } 18\end{array}$ \\
\hline & & & & & Frey 41.7 & Frey $6.6 \mathrm{yr}$ & & \\
\hline & & & & & PPPD $51.5 \pm 10.5$ & PPPD $38.1 \pm 48.6 \mathrm{~m}$ & & \\
\hline
\end{tabular}

PPPD, pylorus-preserving pancreaticoduodenectomy; DP, distal pancreatectomy; $P D$, pancreaticoduodenectomy; OPPHR, organ-preserving pancreatic head resection; DPPHR,

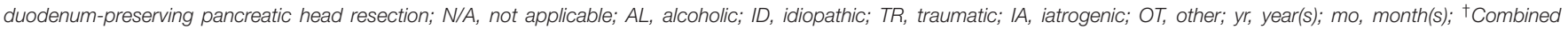
with two groups; ' with enlargement but size not mentioned.

Berne modification. Four studies compared the Beger procedure with PPPD. Two studies compared the Berne modification with PPPD. The differences and similarities of the operations for $\mathrm{CP}$ are shown in Table 3. The Cochrane Collaboration tool for assessing risk of bias (Table 4) showed that all studies had no domain with a high risk of bias, and 5 studies had no information about how randomization was performed.

\section{Postoperative Pain Relief}

Eight studies reported postoperative pain relief data. Three of them reported long-term follow-up results (Figure 2A). The results of NMA for postoperative pain relief are showed in Figure 3A. We found that patients receiving PPPD had significant short-term postoperative pain relief compared to other surgical procedures (PPPD vs. Frey: OR $=0.61,95 \% \mathrm{CI}$ 0.13-2.6; Beger vs. PPPD: OR $=1.4,95 \%$, CI 0.62-3.3, Berne vs. PPPD: $\mathrm{OR}=1.2,95 \% \mathrm{CI} 0.26-5.3)$. The effect of Beger was similar to Frey (Beger vs. Frey: OR $=0.86,95 \%$ CI 0.19-3.8) and Berne (Berne vs. Beger: $\mathrm{OR}=0.86,95 \% \mathrm{CI} 0.19-3.6$ ). The possibility value of different ranking of each surgical approach is showed in Figure 4A. The highest probability of being ranked first for short-term postoperative pain relief was PPPD, followed by Berne, Frey and Beger.

For Long-term postoperative pain relief (Figure 2B), the NMA results showed that Berne had the highest possibility of being first rank for long-term pain relief and the worst treatment was Frey (Figure 4B). Compared to other treatments, Frey also had the worse long-term pain relief (PPPD vs. Frey: mean difference:0.37, 95\% CI -10.0 to 12.0 ; Beger vs. Frey: mean difference $-0.74,95 \%$ CI -11.0 to 10.0 ; Figure 3B).

\section{Quality of Life}

Four studies reported QOL using the SF-36 QOL instrument (Figure 2C). The NMA results of postoperative QOL are summarized in Figure 3C. We found that PPPD and Frey had the highest probability of being ranked first for QOL (Figure 4C) and both surgical procedures had significantly differences compared to Beger (Beger vs. PPPD: mean difference 3.5, 95\% CI -9.8 to 17.0; Beger vs. Frey: mean difference $3.9,95 \%$ CI -6.3 to 15.0 ).
TABLE 3 | Differences and similarities of the operations for CP.

\begin{tabular}{|c|c|c|c|}
\hline & $\begin{array}{l}\text { Extent of } \\
\text { resection }\end{array}$ & $\begin{array}{l}\text { Ductal } \\
\text { decompression }\end{array}$ & $\begin{array}{l}\text { Methods of } \\
\text { anastomisis }\end{array}$ \\
\hline PPPD & $\begin{array}{l}\text { Total pancreatic } \\
\text { head, partial } \\
\text { duodenal, } \\
\text { common bile duct }\end{array}$ & Transection & $\begin{array}{l}\text { End-to-side } \\
\text { pancreaticojejunostomy, } \\
\text { choledochojejunostomy } \\
\text { and } \\
\text { jejunoduodenostomy }\end{array}$ \\
\hline $\begin{array}{l}\text { Beger } \\
\text { procedure }\end{array}$ & $\begin{array}{l}\text { Almost all of the } \\
\text { pancreatic head }\end{array}$ & Transection & $\begin{array}{l}\text { End-to-side } \\
\text { pancreaticojejunostomy }\end{array}$ \\
\hline $\begin{array}{l}\text { Berne } \\
\text { modification }\end{array}$ & $\begin{array}{l}\text { Partial pancreatic } \\
\text { head }\end{array}$ & $\begin{array}{l}\text { Wide opening } \\
\text { in the } \\
\text { pancreatic head }\end{array}$ & $\begin{array}{l}\text { End-to-side } \\
\text { pancreaticojejunostomy }\end{array}$ \\
\hline $\begin{array}{l}\text { Frey } \\
\text { modification }\end{array}$ & $\begin{array}{l}\text { Partial pancreatic } \\
\text { head }\end{array}$ & $\begin{array}{l}\text { Longitudinal } \\
\text { opening the } \\
\text { pancreatic duct }\end{array}$ & $\begin{array}{l}\text { Side-to-side } \\
\text { pancreaticojejunostomy }\end{array}$ \\
\hline
\end{tabular}

\section{Pancreatic Function}

Seven studies reported data on pancreatic exocrine function after surgery (Figure 2D) In Figure 3D, PPPD had significant postoperative pancreatic exocrine function deficiency (PPPD vs. Frey: OR 3.6; Beger vs. PPPD: OR 0.22; Berne vs. PPPD: OR 0.25). The effect of Berne is similar to Beger (Berne vs. Beger: OR 1.1). Berne and Frey had a better prognosis in postoperative pancreatic exocrine function deficiency, while PPPD are easier link to worse pancreatic exocrine function (Figure 4D).

Eight studies reported available data about new-onset diabetes after surgery (Figure 2E). The possibility value of the difference rankings of each surgical procedure (Figure 4E) shows the best treatment is Beger and the worst treatment is Frey. In Figure 3E, Beger had the relatively low risk of postoperative pancreatic endocrine function deficiency (Beger vs. PPPD: OR $=0.5295 \%$ CI 0.17-1.3; Beger vs. Frey: OR $=0.36,95 \%$ CI 0.076-1.5; Berne vs. Beger: $\mathrm{OR}=1.3,95 \%$ CI $0.26-4.8$ ).

\section{Morbidity}

Eight studies reported available data about morbidity (Figure 2F). The NMA results showed that PPPD had the higher morbidity compared with other treatment (PPPD vs. 
TABLE 4 | The Cochrane Collaboration's tool for assessing risk of bias of RCTs.

\begin{tabular}{|c|c|c|c|c|c|c|c|c|}
\hline & Study & $\begin{array}{l}\text { Random } \\
\text { sequence } \\
\text { generation }\end{array}$ & $\begin{array}{l}\text { Allocation } \\
\text { concealment }\end{array}$ & $\begin{array}{l}\text { Blinding of } \\
\text { participants }\end{array}$ & $\begin{array}{l}\text { Blinding of } \\
\text { outcome } \\
\text { assessment }\end{array}$ & $\begin{array}{l}\text { Incomplete } \\
\text { outcome } \\
\text { data }\end{array}$ & $\begin{array}{l}\text { Selective } \\
\text { reporting }\end{array}$ & Other bias \\
\hline 1.1 & $\begin{array}{l}\text { J. R. Izbicki and C. E. } \\
\text { Broelsch }\end{array}$ & Low risk & Low risk & Low risk & Low risk & Low risk & Low risk & Low risk \\
\hline 1.2 & $\begin{array}{l}\text { Tim Strate and J. R. } \\
\text { Izbicki et al. }\end{array}$ & Low risk & Low risk & Low risk & Low risk & Low risk & Low risk & Low risk \\
\hline 1.3 & $\begin{array}{l}\text { K. Bachmann and J. R. } \\
\text { Izbicki et al. }\end{array}$ & Low risk & Low risk & Low risk & Low risk & Low risk & Low risk & Low risk \\
\hline 2.1 & $\begin{array}{l}\text { J. R. Izbicki and C. E. } \\
\text { Broelsch }\end{array}$ & Low risk & Low risk & Low risk & Low risk & Low risk & Low risk & Low risk \\
\hline 2.2 & $\begin{array}{l}\text { J. R. Izbicki and C. E. } \\
\text { Broelsch et al. }\end{array}$ & Low risk & Low risk & Low risk & Low risk & Low risk & Low risk & Low risk \\
\hline 2.3 & $\begin{array}{l}\text { C. Bloechle and J. R. } \\
\text { Izbicki }\end{array}$ & Low risk & Low risk & Low risk & Low risk & Low risk & Low risk & Low risk \\
\hline 2.4 & $\begin{array}{l}\text { Tim Strate and J. R. } \\
\text { Izbicki et al. }\end{array}$ & Low risk & Low risk & Low risk & Low risk & Low risk & Low risk & Low risk \\
\hline 2.5 & $\begin{array}{l}\text { K. Bachmann and O. } \\
\text { Mann }\end{array}$ & Low risk & Low risk & Low risk & Low risk & Low risk & Low risk & Low risk \\
\hline 3.1 & $\begin{array}{l}\text { Marcus W. Buchler and } \\
\text { Hans G. Beger }\end{array}$ & Unclear & Unclear & Low risk & Low risk & Low risk & Low risk & Low risk \\
\hline 3.2 & $\begin{array}{l}\text { M. W. Muller and M. W. } \\
\text { Buchler }\end{array}$ & Unclear & Unclear & Low risk & Low risk & Low risk & Low risk & Low risk \\
\hline 4 & $\begin{array}{l}\text { Michael W. Muller and } \\
\text { Markus W. Buchler }\end{array}$ & Unclear & Unclear & Low risk & Low risk & Low risk & Low risk & Low risk \\
\hline 5.1 & $\begin{array}{l}\text { Jorg Koninger and } \\
\text { Markus W. Buchler }\end{array}$ & Low risk & Low risk & Low risk & Low risk & Low risk & Low risk & Low risk \\
\hline 5.2 & $\begin{array}{l}\text { Ulla Klaiber and Markus } \\
\text { K. Diener }\end{array}$ & Low risk & Low risk & Low risk & Low risk & Low risk & Low risk & Low risk \\
\hline 6 & $\begin{array}{l}\text { Tobias Keck and Ulrich T. } \\
\text { Hopt }\end{array}$ & Unclear & Unclear & Low risk & Low risk & Low risk & Low risk & Low risk \\
\hline 7 & $\begin{array}{l}\text { Gyula Farkas and Gyula } \\
\text { Farkas Jr. }\end{array}$ & Unclear & Unclear & Low risk & Low risk & Low risk & Low risk & Low risk \\
\hline 8 & I. Klempa and W. Arnold & Low risk & Low risk & Low risk & Low risk & Low risk & Low risk & Low risk \\
\hline 9 & Tsann-Long Hwang & Low risk & Low risk & Low risk & Low risk & Low risk & Low risk & Low risk \\
\hline 10 & $\begin{array}{l}\text { J. R. Izbicki and C. E. } \\
\text { Broelsch }\end{array}$ & Low risk & Low risk & Low risk & Low risk & Low risk & Low risk & Low risk \\
\hline 11 & M. K. Diener & Low risk & Low risk & Low risk & Low risk & Low risk & Low risk & Low risk \\
\hline
\end{tabular}

Frey: $\mathrm{OR}=3.9,95 \%$ CI 0.13-48.0; Beger vs. PPPD: OR = 0.54, 95\% CI 0.095-2.0; Berne vs. PPPD: OR $=0.18,95 \% \mathrm{CI}$ 0.0045-1.40; Figure 3F). In Figure 4F, we found that Berne had the highest possibility value of being ranked first for morbidity, followed by Frey, Beger, and PPPD.

\section{Long-Term Mortality}

Five studies reported more than 10 years of available data about long-term mortality (Figure 2G). In Figure 4G, the ranking of these 4 treatment showed that the best treatment is Berne and the worst treatment is Beger. From the result of NMA, Beger had the significant worse long-term mortality (Beger vs. Frey: mean difference $=0.25,95 \% \mathrm{CI}-0.52$ to 1.1 ; Beger vs. PPPD: mean difference $0.38,95 \%$ CI -0.34 to 1.0 ; Figure 3G).

\section{Operation Time}

Six studies reported available data about operation time (Figure 2H). As shown in Figure 3H, the Frey modification was associated with a higher likelihood of the reduced operation time than the Beger procedure, but no significant difference was found between the two sets of procedures Compared with PPPD, the Frey modification required a shorter operation time. In the resection vs. resection group, Beger procedures achieved a shorter operation time than PPPD procedure. The Berne modification tended to have a shorter operation time than the PPPD procedure. The Berne modification also achieved a shorter operation time than the Beger procedure (Figure $4 \mathbf{H}$ ).

\section{DISCUSSION}

The most common and predominant symptom of CP is pain and the first goal of the treatment of CP is to resolve this intractable pain. To achieve this result, we need to eliminate the cause of the pain, which is now considered to be chronic inflammation. Chronic inflammation induces not only pancreatic neuritis, 


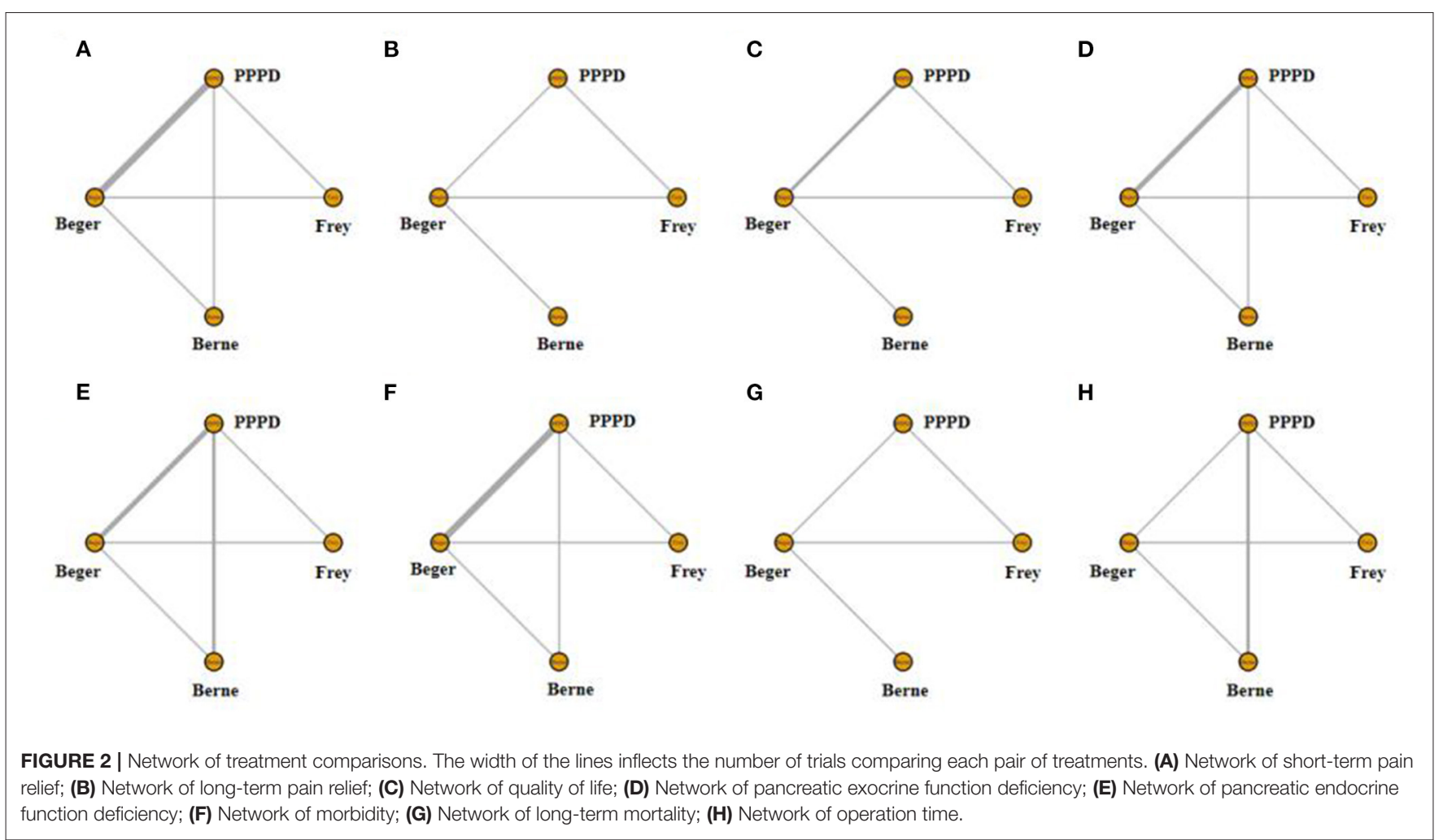

fibrosis and ductal hypertension $(9,44,45)$; ductal hypertension may further exacerbate inflammation (46).

The ideal procedure to treat $\mathrm{CP}$ should relieve the pain for a long time, preserve most pancreatic function and provide a high quality of life with a less invasive operation and less trauma (47). Now we have several treatments for CP: medicine, endoscopy and surgery. Medicine and endoscopy are easy to carry out without pancreas damage. However, they cannot offer long-term pain relief (10-12) and cannot reduce the incidence of pancreatic adenocarcinoma when compared with surgery. Therefore, surgery is an effective choice for the treatment of CP. Even early surgery (13-15) may be an option for treating CP.

Many surgical procedures have been developed for $\mathrm{CP}$, such as the Whipple procedure, Beger procedure, Berne modification, Frey modification and so on. All of these surgeries focus on ductal decompression to alleviate pain from obstruction and to prevent inflammatory consequences in the surrounding tissue (48-50). However, the best option for CP remains controversial. Several systematic reviews have been performed to compare the efficacy of these procedures; however, most of them compared just two procedures or included retrospective studies. Here, we compared all of the surgical procedures for CP with only RCT studies. We hope to provide high-quality evidence regarding the best options of surgical procedures for $\mathrm{CP}$.

Our network meta-analysis results showed PPPD had a significantly short-term pain relief and Berne had a higher pain relief effect during long-term follow-up. Besides, the Berne modification also had a relatively better short-term pain relief compared to the Frey modification and Beger procedure.

We also compared QOL, pancreatic exocrine function, new-onset diabetes, long-term mortality and morbidity of
CP patients among the surgical procedures. Both PPPD and Frey modification had similar effect on postoperative QOL, but according to our results these two surgical procedures had significant high risk of postoperative pancreatic function deficiency (exocrine function or endocrine function). Compared to other procedures, the Berne modification had relatively low risk of pancreatic function deficiency, but a worse postoperative QOL and lower long-term mortality.

The Beger procedure and PPPD are more complicated surgical procedures than the Frey modification and Berne modification. The Beger procedure and PPPD not only lead to far longer operation times, intensive care monitoring and hospitalization times but also necessitate more frequent blood transfusions (51).

Some studies have reported that patients who underwent PPPD had a high morbidity, i.e., up to 50\% (30), and high pancreatic exocrine or/and endocrine dysfunction rates (52). The loss of disease-free neighboring organs is an additional disadvantage of PPPD (30) and frequently leads to dumping complaints and episodes of cholangitis (53). According to our results, although PPPD had a better short-term pain relief, but the effect for long-term pain relief is not good with high risk of pancreatic function deficiency. All of these results indicate that PPPD may not be the best choice for CP with prolonged operation time, raised comorbidity rates and less effect on pain control than organ-preserving surgical procedures.

Based on our results, the Berne modification had a significantly long-term pain relief, relatively low risk of postoperative pancreatic function deficiency and lower long-term mortality. All three of these procedures are organ-preserving surgical procedures. However, the Beger procedure resects the pancreatic head completely; the Frey modification and Berne 
A

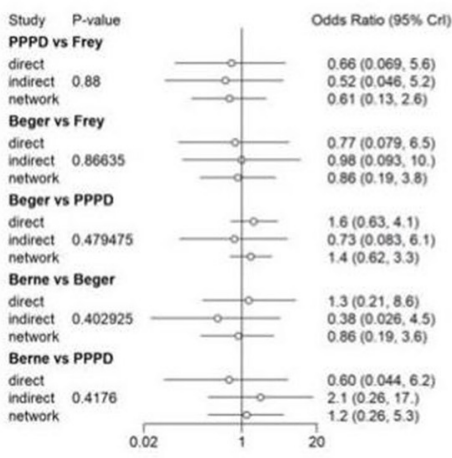

C

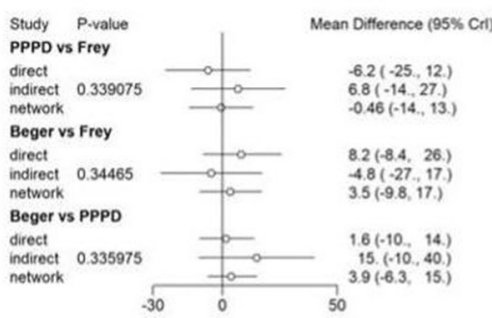

E

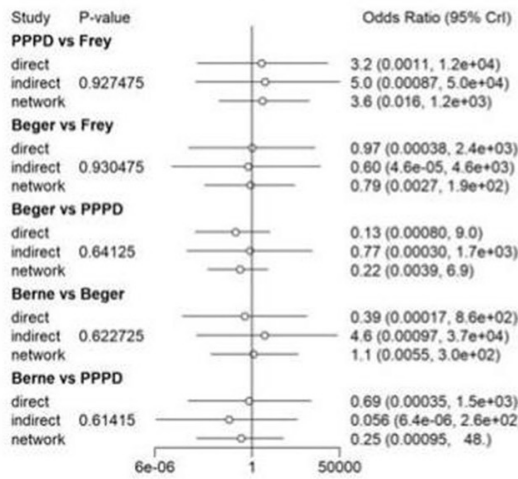

G

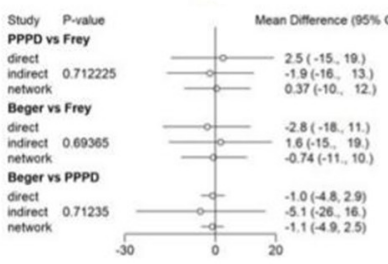

B

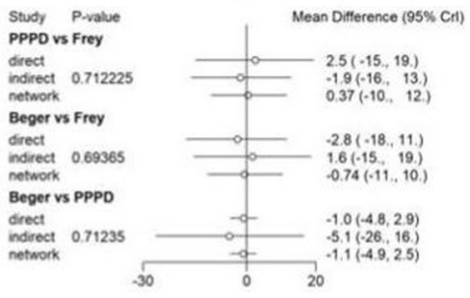

D

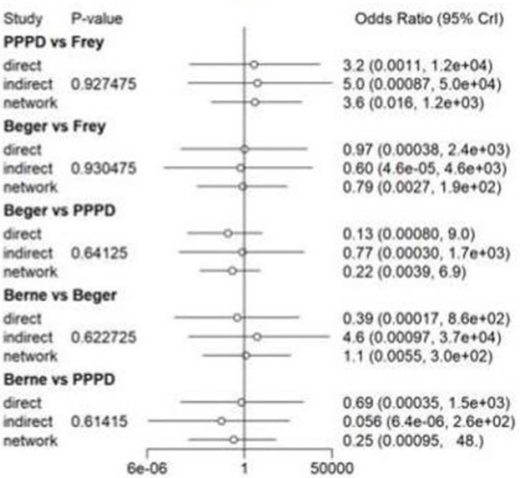

F

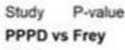
PPPD vs Frey

direct

indirect 0.79505

Beger vs Frey

Girect 0.789

network 0.789

Beger vs PPPD

direct

indirect 0.112

Berne vs Beger

direct

indirect 0.00155

Berne vs PPPD

direct

indirect 0.001275

H

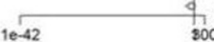

Odds Ratio (95\% Crr)

$5.1(0.12,2.3 e+02)$

$3.9(0.43,48$.)

$1.6(0.039,67$.

$2.1(0.19,20)$

$0.86(0.16,3.7)$

$0.097(0.00097,1.2)$

$1.2(0.16,8.6)$

$9.6 \mathrm{e}-17(1.9 \mathrm{e}-42,0.017)$

$0.33(0.013,2.7)$

$1.0 \mathrm{e}-15(2.1 \mathrm{e}-37,0.0072)$ $0.90(0.090,8.1)$

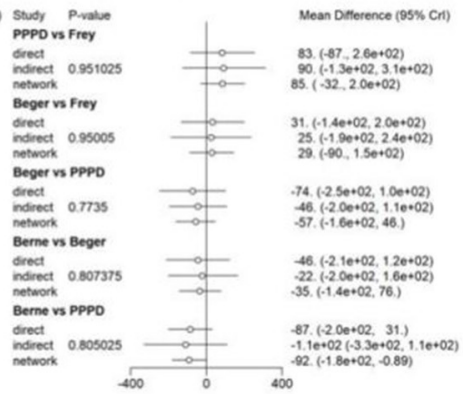

FIGURE 3 | Forest plot of treatment comparisons. The results of continuous variables were estimated as weighted mean difference (WMD) with their corresponding 95\% confidence interval (Cl), while categorical variables were expressed as odds ratio (OR) with 95\% Cl. (A) Forest plot of short-term pain relief; (B) Forest plot of long-term pain relief; (C) Forest plot of quality of life; (D) Forest plot of pancreatic exocrine function deficiency; (E) Forest plot of pancreatic endocrine function deficiency; (F) Forest plot of morbidity; (G) Forest plot of long-term mortality; (H) Forest plot of operation time. 


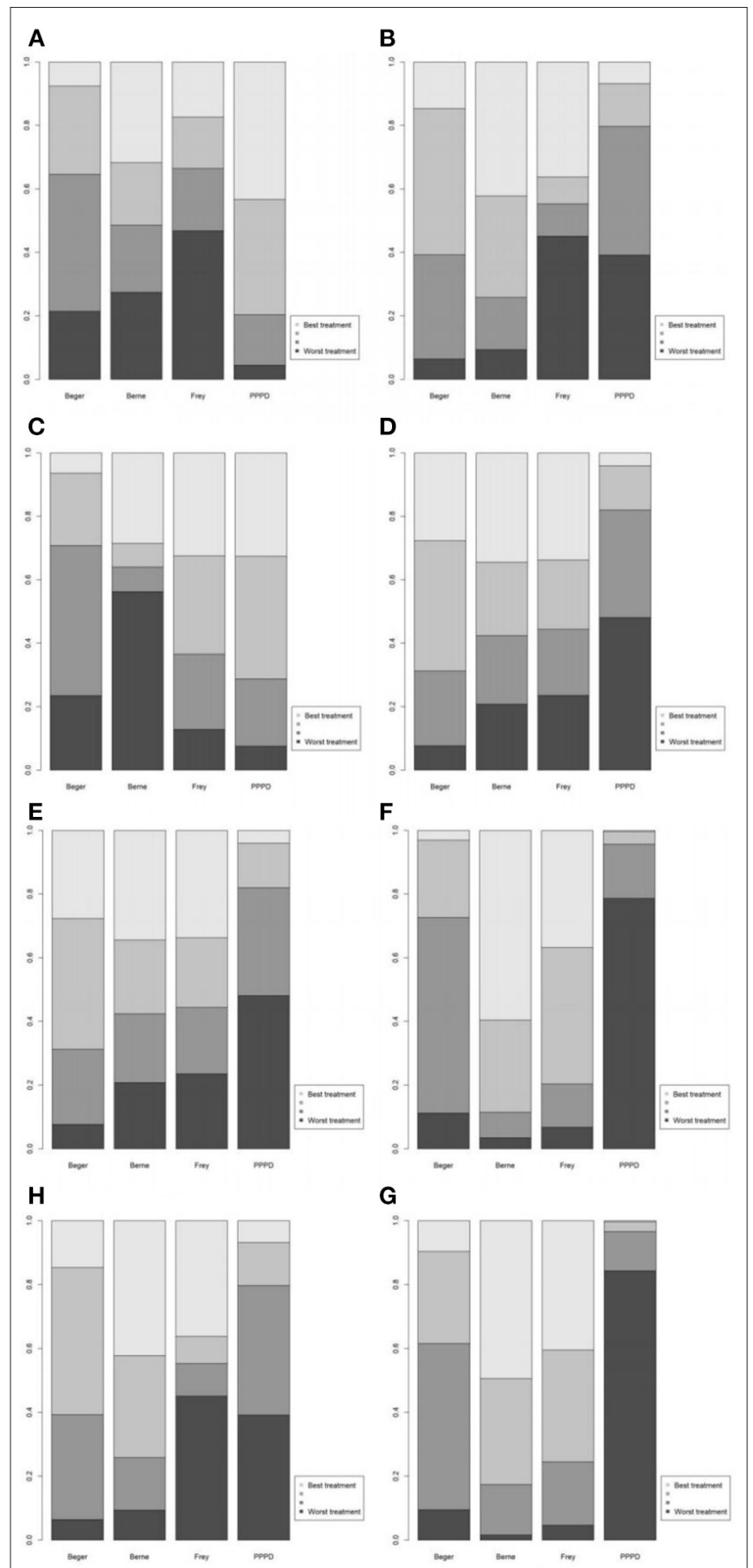

FIGURE 4 | Values of different ranking of the surgical procedures. (A) Short-term pain relief; (B) long-term pain relief; (C) quality of life; (D) pancreatic exocrine function deficiency; (E) pancreatic endocrine function deficiency; (F) morbidity; (G) long-term mortality; (H) operation time.

modification only require a local or subtotal excision of the pancreatic head $(30,54)$. Therefore, the Frey modification and Berne modification are easier than the Beger procedure. Several studies have reported that the Frey modification requires a shorter operation time and requires less transfused blood units than the Beger procedure $(20,53)$. One meta-analysis that included one RCT and two non-RCTs reported that the Frey modification had a lower morbidity than the Beger procedure (20). Although there was no difference in the morbidity of the Berne modification and that of the Beger procedure even after the 10-year follow-up (36), surgery could be performed significantly faster with the Berne modification. The total length of hospital stay was also shorter following the Berne modification. These results indicated that the Berne modifications might be safer for patients and had a better effect on pain relief.

There are several limitations to this meta-analysis. First, although only RCTs were enrolled in this study, some of them did not report the methods of randomization and concealment in detail. Then, the main surgical treatments of CP focus on the removal of the mass of the pancreatic head and drainage to relieve the pain and to preserve pancreatic function. Although one study (41) showed a better treatment outcome of distal pancreatectomy with end-to-side pancreaticojejunostomy than PPPD in patients with small pancreatic duct, distal pancreatectomy is not a surgical technique regularly used for the treatment of most CP patients.

\section{CONCLUSION}

In summary, the main surgical procedures including PPPD, the Beger procedure, the Frey modification and the Berne modification can efficaciously treat $\mathrm{CP}$, not only in the short term but also in the long term. Furthermore, the Berne modification are easier procedures than PPPD and the Beger procedure. However, the Berne modification may lead to poor QOL after surgery. In addition, when CP patients have a mass in the head of the pancreas that cannot be distinguished from pancreatic cancer, based on our experience, PPPD or classical pancreaticoduodenectomy should be the only legitimate choice.

\section{DATA AVAILABILITY STATEMENT}

The raw data supporting the conclusions of this article will be made available by the authors, without undue reservation.

\section{AUTHOR CONTRIBUTIONS}

$\mathrm{N}-\mathrm{WK}$ and $\mathrm{X}-\mathrm{BL}$ designed the study. H-YC and YS acquired the data. WH adjudicated when the consensus of two authors failed. XW analyzed and interpreted the data. YM and YS wrote the paper. N-WK critically revised the manuscript for important intellectual content. All authors contributed to the article and approved the submitted version.

\section{FUNDING}

This research was supported by Sichuan Province Science and Technology Planning Project (2020YFS0262), West China Hospital Clinical Research Incubation Project (21HXFH058), and the 1.3.5 Project for Disciplines of Excellence-Clinical Research Incubation Project (ZY2017302 and ZYJC21037), West China Hospital, Sichuan University. 


\section{REFERENCES}

1. Majumder S, Chari ST. Chronic pancreatitis. Lancet. (2016) 387:195766. doi: 10.1016/S0140-6736(16)00097-0

2. Kamisawa T, Wood LD, Itoi T, Takaori K. Pancreatic cancer. Lancet. (2016) 388:73-85. doi: 10.1016/S0140-6736(16)00141-0

3. Levy P, Dominguez-Munoz E, Imrie C, Lohr $\mathrm{M}$, Maisonneuve P. Epidemiology of chronic pancreatitis: burden of the disease and consequences. United European Gastroenterol J. (2014) 2:345-54. doi: 10.1177/2050640614548208

4. Peery AF, Crockett SD, Barritt AS, Dellon ES, Eluri S, Gangarosa LM, et al. Burden of gastrointestinal, liver, and pancreatic diseases in the United States. Gastroenterology. (2015) 149:1731-41.e3. doi: 10.1053/j.gastro.2015.08.045

5. Anderson MA, Akshintala V, Albers KM, Amann ST, Belfer I, Brand R, et al. Mechanism, assessment and management of pain in chronic pancreatitis: recommendations of a multidisciplinary study group. Pancreatology. (2016) 16:83-94. doi: 10.1016/j.pan.2015.10.015

6. Forsmark CE. Management of chronic pancreatitis. Gastroenterology. (2013) 144:1282-91.e3. doi: 10.1053/j.gastro.2013.02.008

7. Issa Y, Bruno MJ, Bakker OJ, Besselink MG, Schepers NJ, van Santvoort HC, et al. Treatment options for chronic pancreatitis. Nat Rev Gastroenterol Hepatol. (2014) 11:556-64. doi: 10.1038/nrgastro.2014.74

8. Jamison RN, Mao J. Opioid analgesics. Mayo Clin Proc. (2015) 90:95768. doi: 10.1016/j.mayocp.2015.04.010

9. Demir IE, Tieftrunk E, Maak M, Friess H, Ceyhan GO. Pain mechanisms in chronic pancreatitis: of a master and his fire. Langenbecks Arch Surg. (2011) 396:151-60. doi: 10.1007/s00423-010-0731-1

10. Dite P, Ruzicka M, Zboril V, Novotny I. A prospective, randomized trial comparing endoscopic and surgical therapy for chronic pancreatitis. Endoscopy. (2003) 35:553-8. doi: 10.1055/s-2003-40237

11. Cahen DL, Gouma DJ, Nio Y, Rauws EA, Boermeester MA, Busch OR, et al. Endoscopic versus surgical drainage of the pancreatic duct in chronic pancreatitis. N Engl J Med. (2007) 356:676-84. doi: 10.1056/ NEJMoa060610

12. Cahen DL, Gouma DJ, Laramee P, Nio Y, Rauws EA, Boermeester MA, et al. Long-term outcomes of endoscopic vs. surgical drainage of the pancreatic duct in patients with chronic pancreatitis. Gastroenterology. (2011) 141:16905. doi: 10.1053/j.gastro.2011.07.049

13. Kadam PD, Chuan HH. Erratum to: Rectocutaneous fistula with transmigration of the suture: a rare delayed complication of vault fixation with the sacrospinous ligament. Int Urogynecol J. (2016) 27:505. doi: 10.1007/s00192-016-2952-5

14. Yang CJ, Bliss LA, Schapira EF, Freedman SD, Ng SC, Windsor JA, et al. Systematic review of early surgery for chronic pancreatitis: impact on pain, pancreatic function, and re-intervention. J Gastrointest Surg. (2014) 18:18639. doi: 10.1007/s11605-014-2571-8

15. Yang CJ, Bliss LA, Freedman SD, Sheth S, Vollmer CM, Ng SC, et al. Surgery for chronic pancreatitis: the role of early surgery in pain management. Pancreas. (2015) 44:819-23. doi: 10.1097/MPA.0000000000000333

16. Gurusamy KS, Lusuku C, Halkias C, Davidson BR. Duodenumpreserving pancreatic resection versus pancreaticoduodenectomy for chronic pancreatitis. Cochrane Database Syst Rev. (2016) 2:CD011521. doi: 10.1002/14651858.CD011522.pub2

17. Lu WP, Shi Q, Zhang WZ, Cai SW, Jiang K, Dong JH. A meta-analysis of the long-term effects of chronic pancreatitis surgical treatments: duodenumpreserving pancreatic head resection versus pancreatoduodenectomy. Chin Med J. (2013) 126:147-53. doi: 10.3760/cma.j.issn.0366-6999.20112607

18. Sukharamwala PB, Patel KD, Teta AF, Parikh S, Ross SB, Ryan CE, et al. Long-term outcomes favor duodenum-preserving pancreatic head resection over pylorus-preserving pancreaticoduodenectomy for chronic pancreatitis: a meta-analysis and systematic review. Am Surg. (2015) 81:90914. doi: 10.1177/000313481508100927

19. Zhao X, Cui N, Wang X, Cui Y. Surgical strategies in the treatment of chronic pancreatitis: an updated systematic review and meta-analysis of randomized controlled trials. Medicine. (2017) 96:e6220. doi: 10.1097/MD.0000000000006220

20. Zhou Y, Shi B, Wu L, Wu X, Li Y. Frey procedure for chronic pancreatitis: Evidence-based assessment of short- and long-term results in comparison to pancreatoduodenectomy and Beger procedure: a metaanalysis. Pancreatology. (2015) 15:372-9. doi: 10.1016/j.pan.2015.05.466

21. Hozo SP, Djulbegovic B, Hozo I. Estimating the mean and variance from the median, range, and the size of a sample. BMC Med Res Methodol. (2005) 5:13. doi: 10.1186/1471-2288-5-13

22. Higgins JP, Thompson SG, Deeks JJ, Altman DG. Measuring inconsistency in meta-analyses. BMJ. (2003) 327:557-60. doi: 10.1136/bmj.327.7414.557

23. Demets DL. Methods for combining randomized clinical trials: strengths and limitations. Stat Med. (1987) 6:341-50. doi: 10.1002/sim.4780060325

24. DerSimonian R, Laird N. Meta-analysis in clinical trials. Control Clin Trials. (1986) 7:177-88. doi: 10.1016/0197-2456(86)90046-2

25. Izbicki JR, Bloechle C, Broering DC, Knoefel WT, Kuechler T, Broelsch CE. Extended drainage versus resection in surgery for chronic pancreatitis: a prospective randomized trial comparing the longitudinal pancreaticojejunostomy combined with local pancreatic head excision with the pylorus-preserving pancreatoduodenectomy. Ann Surg. (1998) 228:771-9. doi: 10.1097/00000658-199812000-00008

26. Strate T, Bachmann K, Busch P, Mann O, Schneider C, Bruhn JP, et al. Resection vs. drainage in treatment of chronic pancreatitis: longterm results of a randomized trial. Gastroenterology. (2008) 134:140611. doi: 10.1053/j.gastro.2008.02.056

27. Bachmann K, Tomkoetter L, Kutup A, Erbes J, Vashist Y, Mann O, et al. Is the Whipple procedure harmful for long-term outcome in treatment of chronic pancreatitis? 15-years follow-up comparing the outcome after pylorus-preserving pancreatoduodenectomy and Frey procedure in chronic pancreatitis. Ann Surg. (2013). 258:815-20; discussion: 20 1. doi: 10.1097/SLA.0b013e3182a655a8

28. Izbicki JR, Bloechle C, Knoefel WT, Kuechler T, Binmoeller KF, Broelsch CE. Duodenum-preserving resection of the head of the pancreas in chronic pancreatitis. A prospective, randomized trial. Ann Surg. (1995) 221:3508. doi: 10.1097/00000658-199504000-00004

29. Bloechle C, Busch C, Tesch C, Nicolas V, Binmoeller KF, Soehendra N, et al. Prospective randomized study of drainage and resection on non-occlusive segmental portal hypertension in chronic pancreatitis. Br J Surg. (1997) 84:477-82. doi: 10.1046/j.1365-2168.1997.02635.x

30. Izbicki JR, Bloechle C, Knoefel WT, Kuechler T, Binmoeller FK, Soehendra $\mathrm{N}$, et al. Drainage versus Resektion in der chirurgischen Therapie der chronischen Kopfpankreatitis: eine randomisierte Studie. Chirurg. (1997) 68:369-77. doi: 10.1007/s001040050200

31. Strate T, Taherpour Z, Bloechle C, Mann O, Bruhn JP, Schneider C, et al. Long-term follow-up of a randomized trial comparing the Beger and Frey procedures for patients suffering from chronic pancreatitis. Ann Surg. (2005) 241:591-8. doi: 10.1097/01.sla.0000157268.78543.03

32. Bachmann K, Tomkoetter L, Erbes J, Hofmann B, Reeh M, Perez D, et al. Beger and Frey procedures for treatment of chronic pancreatitis: comparison of outcomes at 16-year follow-up. J Am Coll Surg. (2014) 219:20816. doi: 10.1016/j.jamcollsurg.2014.03.040

33. Buchler MW, Friess H, Muller MW, Wheatley AM, Beger HG. Randomized trial of duodenum-preserving pancreatic head resection versus pyloruspreserving Whipple in chronic pancreatitis. Am J Surg. (1995) 169:65-9; discussion 9-70. doi: 10.1016/S0002-9610(99)80111-1

34. Muller MW, Friess H, Martin DJ, Hinz U, Dahmen R, Buchler MW. Longterm follow-up of a randomized clinical trial comparing Beger with pyloruspreserving Whipple procedure for chronic pancreatitis. Br J Surg. (2008) 95:350-6. doi: 10.1002/bjs.5960

35. Muller MW, Friess H, Beger HG, Kleeff J, Lauterburg B, Glasbrenner B, et al. Gastric emptying following pylorus-preserving Whipple and duodenumpreserving pancreatic head resection in patients with chronic pancreatitis. Am J Surg. (1997) 173:257-63. doi: 10.1016/S0002-9610(96)00402-3

36. Koninger J, Seiler CM, Sauerland S, Wente MN, Reidel MA, Muller MW, et al. Duodenum-preserving pancreatic head resection-a randomized controlled trial comparing the original Beger procedure with the Berne modification (ISRCTN No. 50638764). Surgery. (2008). 143:490-8. doi: 10.1016/j.surg.2007.12.002

37. Klaiber U, Alldinger I, Probst P, Bruckner T, Contin P, Koninger J, et al. Duodenum-preserving pancreatic head resection: 10-year follow-up of a randomized controlled trial comparing the Beger procedure with the Berne modification. Surgery. (2016) 160:127-35. doi: 10.1016/j.surg.2016.02.028 
38. Keck T, Adam U, Makowiec F, Riediger H, Wellner U, Tittelbach-Helmrich D, et al. Short- and long-term results of duodenum preservation versus resection for the management of chronic pancreatitis: a prospective, randomized study. Surgery. (2012) 152(3 Suppl 1):S95-102. doi: 10.1016/j.surg.2012.05.016

39. Farkas G, Leindler L, Daroczi M, Farkas G Jr. Prospective randomised comparison of organ-preserving pancreatic head resection with pyloruspreserving pancreaticoduodenectomy. Langenbecks Arch Surg. (2006). 391:338-42. doi: 10.1007/s00423-006-0051-7

40. Klempa I, Spatny M, Menzel J, Baca I, Nustede R, Stoeckmann F, et al. Pankreasfunktion und Lebensqualität nach Pankreaskopfresektion bei der chronischen Pankreatitis: eine prospektive, randomisierte Vergleichsstudie nach duodenumerhaltender Pankreaskopfresektion versus Whipple'scher Operation. Chirurg. (1995) 66:350-9.

41. Hwang TL, Chen HM, Chen MF. Surgery for chronic obstructive pancreatitis: comparison of end-to-side pancreaticojejunostomy with pancreaticoduodenectomy. Hepatogastroenterology. (2001) 48:270-2.

42. Izbicki JR, Knoefel WT, Bloechle C, Kuchler T, Kuhn R, Limmer JC, et al. Stellenwart duodenumerhaltender pankreaskopfresektionen in der therapie der chronischen Pankreatitis. Zentralbl Chir. (1995) 120:298-305.

43. Diener MK, Huttner FJ, Kieser M, Knebel P, Dorr-Harim C, Distler M, et al. Partial pancreatoduodenectomy versus duodenum-preserving pancreatic head resection in chronic pancreatitis: the multicentre, randomised, controlled, double-blind ChroPac trial. Lancet. (2017) 390:1027-37. doi: 10.1016/S0140-6736(17)31960-8

44. Demir IE, Friess H, Ceyhan GO. Neural plasticity in pancreatitis and pancreatic cancer. Nat Rev Gastroenterol Hepatol. (2015) 12:64959. doi: 10.1038/nrgastro.2015.166

45. Muniraj T, Aslanian HR, Farrell J, Jamidar PA. Chronic pancreatitis, a comprehensive review and update. Part I: epidemiology, etiology, risk factors, genetics, pathophysiology, and clinical features. Dis Mon. (2014) 60:53050. doi: 10.1016/j.disamonth.2014.11.002

46. Deviere J, Bell RH Jr, Beger HG, Traverso LW. Treatment of chronic pancreatitis with endotherapy or surgery: critical review of randomized control trials. J Gastrointest Surg. (2008) 12:640-4. doi: 10.1007/s11605-007-0448-9

47. Bachmann K, Izbicki JR, Yekebas EF. Chronic pancreatitis: modern surgical management. Langenbecks Arch Surg. (2011) 396:139-49. doi: 10.1007/s00423-010-0732-0

48. Beger HG, Schlosser W, Friess HM, Buchler MW. Duodenum-preserving head resection in chronic pancreatitis changes the natural course of the disease: a single-center 26-year experience. Ann Surg. (1999) 230:512-9; discussion: 9-23. doi: 10.1097/00000658-199910000-00007

49. Frey CF, Andersen DK. Surgery of chronic pancreatitis. Am J Surg. (2007) 194:S53-60. doi: 10.1016/j.amjsurg.2007.05.026

50. Farkas G, Leindler L, Daroczi M, Farkas G Jr. Long-term follow-up after organ-preserving pancreatic head resection in patients with chronic pancreatitis. J Gastrointest Surg. (2008) 12:308-12. doi: 10.1007/s11605-007-0324-7

51. Hildebrand P, Dudertadt S, Czymek R, Bader FG, Roblick UJ, Bruch HP, et al. Different surgical strategies for chronic pancreatitis significantly improve long-term outcome: a comparative single center study. Eur J Med Res. (2010) 15:351-6. doi: 10.1186/2047-783X-15-8-351

52. Cameron JL, Riall TS, Coleman J, Belcher KA. One thousand consecutive pancreaticoduodenectomies. Ann Surg. (2006) 244:10-5. doi: 10.1097/01.sla.0000217673.04165.ea

53. Beger HG, Schoenberg MH, Link KH, Safi F, Berger D. [Duodenumpreserving pancreatic head resection-a standard method in chronic pancreatitis]. Chirurg. (1997) 68:874-80. doi: 10.1007/s001040050287

54. Ho HS, Frey CF. The Frey procedure: local resection of pancreatic head combined with lateral pancreaticojejunostomy. Arch Surg. (2001) 136:13538. doi: 10.1001/archsurg.136.12.1353

Conflict of Interest: The authors declare that the research was conducted in the absence of any commercial or financial relationships that could be construed as a potential conflict of interest.

Publisher's Note: All claims expressed in this article are solely those of the authors and do not necessarily represent those of their affiliated organizations, or those of the publisher, the editors and the reviewers. Any product that may be evaluated in this article, or claim that may be made by its manufacturer, is not guaranteed or endorsed by the publisher.

Copyright (c) 2022 Mou, Song, Chen, Wang, Huang, Liu and Ke. This is an openaccess article distributed under the terms of the Creative Commons Attribution License (CC BY). The use, distribution or reproduction in other forums is permitted, provided the original author(s) and the copyright owner(s) are credited and that the original publication in this journal is cited, in accordance with accepted academic practice. No use, distribution or reproduction is permitted which does not comply with these terms. 